\title{
Sleep apnoea and driving risk: the need for regulation
}

\author{
Walter T. McNicholas ${ }^{1}$ and Daniel Rodenstein ${ }^{2}$
}

Affiliations: ${ }^{1}$ Dept of Respiratory and Sleep Medicine, St Vincent's University Hospital, School of Medicine and Medical Science, Conway Institute, University College Dublin, Dublin, Ireland. 'Université Catholique de Louvain, Louvain, Belgium.

Correspondence: Walter McNicholas, Pulmonary and Sleep Disorders Unit, St Vincent's University Hospital, Elm Park, Dublin 4, Ireland. E-mail: walter.mcnicholasqucd.ie

ABSTRACT Obstructive sleep apnoea syndrome (OSAS) is a highly prevalent chronic respiratory disorder with prevalence among adult males of $\geqslant 10 \%$. The most common daytime symptom associated with OSAS is excessive sleepiness, which in more severe manifestations can result in sleepiness at the wheel while driving and probably contributes to the substantial increase in accident risk among patients with OSAS. Fortunately, current evidence indicates that successful therapy of OSAS, particularly with continuous positive airway pressure, can bring the accident risk down to levels similar to an equivalent general population. The recognition of the increased driving accident risk in OSAS prompted the Transport and Mobility Directorate of the European Commission to establish a working group on this topic in 2012, which ultimately led to a revision of Annex III of the EU Driving Licence Directive, which is subject to mandatory implementation by European Union member states by December 2015. This directive specifies that patients with moderate or severe OSAS associated with significant daytime sleepiness should be prohibited from driving until effective therapy is established. These new regulations are designed to balance the legitimate objective of public safety with not penalising OSAS patients who are complying with effective therapy. Successful implementation of regulations on driving in OSAS patients must also include measures to educate relevant stakeholders including patients, medical personnel, traffic police and employers in the transport industry. The key objective is to encourage patients with possible OSAS to seek diagnosis and treatment and not to inhibit OSAS patients from coming forward.

@ERSpublications

Driving accidents caused by sleep apnoea reduced by therapy, thus justifying regulation to ensure effective treatment http://ow.ly/St0sV

\section{Introduction}

Motor vehicle accidents (MVAs) are infrequent events arising generally through the simultaneous presence of several different factors that may include excessive speed and the consumption of alcohol, in addition to age and driving distances. Human diseases are another well-known risk factor and several diseases are independently associated with a raised incidence of MVA when compared to the general population $[1,2]$. These include diabetes mellitus, cardiovascular diseases, cerebrovascular diseases, psychiatric conditions, uncorrected visual defects and obesity. Disorders associated with sleep disturbance and sleepiness are also recognised to be associated with increased accident risk [3,4], and obstructive sleep apnoea syndrome (OSAS) is the most prevalent medical disorder associated with excessive sleepiness. OSAS is also associated with increased MVA risk, which exceeds the risk associated with many other medical disorders already specified in driving licence regulations $[1,5]$. The present review discusses the evidence of MVA risk in OSAS, the beneficial impact of treatment on this risk and the recent implementation of regulations by the European Commission (EC) on the rights and duties of patients with OSAS who hold a driving licence.

Received: June 152015 | Accepted: July 032015

Conflict of interest: None declared.

Provenance: Submitted article, peer reviewed.

Copyright OERS 2015. ERR articles are open access and distributed under the terms of the Creative Commons Attribution Non-Commercial Licence 4.0. 


\section{OSAS and MVA risk}

OSAS, a disease characterised by repetitive episodes of upper airway obstruction during sleep [6] results in sleep fragmentation, which consequently results in unrefreshing sleep and excessive daytime sleepiness. The relationship between OSAS and MVA has become increasingly evident during the past two decades, with the increase in MVA risk with respect to a reference population varying between two- and seven-fold in different reports $[7,8]$. The increased risk could be observed for single or multiple accidents and near-miss accidents. The strength of the association between OSAS and accidents was variable between studies, and a recent meta-analysis concluded that the increased accident risk is 2.4 times that of a general population [9].

Despite the strong evidence of increased MVA risk in OSAS patients, reports differ regarding the contribution of disease severity based on the apnoea-hypopnoea index (AHI) or the degree of daytime sleepiness [10]. Methodological differences are also evident in different reports with some comparing the risk of drivers with OSAS to that of a control group, while others compare to the risk of the general population in the relevant jurisdiction. Some studies also took into account possible confounding factors, such as the frequency of driving (distance driven per year), the presence of visual defects, alcohol consumption or obesity. Accident recording also varies between reports with some studies focusing on the prospective assessment of an epidemiological sample, whereas others recorded actual accidents presenting to emergency departments.

\section{Role of sleepiness in OSAS and increased driving risk}

Excessive sleepiness during the day, a key symptom of OSAS, refers to the tendency to doze off or fall asleep in inappropriate situations, and the most extreme example would be to fall asleep in dangerous situations such as while driving. Studies show that excessive sleepiness is involved as a contributing factor in $\sim 5-7 \%$ of all MVAs, with higher estimates of $\sim 17 \%$ in accidents involving fatalities [11]. Accordingly, driving simulator research shows that the performance impairment in drivers suffering from OSAS is comparable to the impairment as a consequence of illegal alcohol consumption or sleep deprivation [12]. While reports differ, the majority of evidence supports the principle that driving risk in OSAS is more closely related to the degree of daytime sleepiness than the objective severity of sleep-disordered breathing as measured by AHI [4,13-15]. The importance of sleepiness as the major contributing factor to MVA risk in OSAS is supported by the recent report of KARIMI et al. [16] who demonstrated that excessive sleepiness based on an Epworth sleepiness score (ESS) >15 significantly related to MVA rate, whereas AHI did not. However, the earlier report of TERÁN-SANTOs et al. [17] found that AHI was more closely related to accident risk than subjective sleepiness based on ESS in a group of 102 patients presenting to hospital following MVAs when compared to a group of matched control subjects. Furthermore, the recent report from the European Sleep Apnoea Database (ESADA) cohort study [18] also found that OSA severity based on AHI was superior to subjective sleepiness based on ESS in predicting accident risk, a finding also reported in an earlier Canadian study [19]. Thus, further research is needed to more clearly define the factors relating to OSAS that predict accident risk.

Other factors that can further increase excessive sleepiness in an OSAS patient include a lack of sleep, time of day (early morning and afternoon), shift work, sedative medications, poor sleep hygiene habits and alcohol use [20], and these additional factors may be particularly important in commercial drivers [21]. Self-reported poor sleep appeared to be particularly important in one recent report from France of 272 patients admitted to hospital following MVA [22]. Since these factors do not directly relate to OSAS severity, they may contribute to some of the variability in reported sleepiness in patients with differing levels of disease severity based on AHI. Thus, patients with OSAS should be particularly warned about these additional risk factors, most of which are avoidable, since these could further increase the risk of MVA.

There are several recognised warning signs that may develop in sleepy drivers short of actual MVA. These include yawning and blinking, nodding at the wheel, an impression of driving automatically with difficulty remembering the past few miles driven and missing planned exits [23]. Furthermore, there may be difficulty in maintaining a steady road position with drifting out of the lane and/or driving on a rumble strip at the road edge in addition to difficulty in maintaining a constant road speed. In these circumstances, many drivers employ countermeasures to limit the effect of drowsy driving, such as winding down the window and taking high-caffeine beverages. However, these measures have limited efficacy and drowsy drivers should be strongly advised to pull over in a rest area and take a 15-20-min nap, and where possible to change drivers.

Several features of MVA increase the likelihood of the accident being related to sleepiness and/or fatigue. These include an absence of brake marks, single-vehicle crash, rear-end or head-on collision, accidents occurring during the night or early afternoon and accidents associated with serious injury or fatality [24]. After in-depth analysis, an estimate of $10 \%$ of all single-vehicle accidents appear to be related to fatigue. 


\section{Effect of therapy on accident risk}

Several reports have assessed the effect on MVA of the treatment of obstructive sleep apnoea with an efficient therapy, generally continuous positive airway pressure (CPAP). These studies used a before-after comparison strategy, with some including a separate group of healthy or general population controls. In almost all studies concerned, effective treatment resulted in substantial decreases, or even normalisation, of the risk of MVA [25]. The report of GEORGE [26] clearly demonstrates the normalisation of MVA risk in OSAS following effective CPAP therapy. In this study from Ontario, Canada, the investigators compared the accident rate of OSAS patients for the 3-year period before diagnosis and the 3-year period after initiating CPAP therapy. They compared the accident rate with the accident rate for the general population during the same 6-year period. They found a three-fold higher accident rate in OSAS patients for the 3-year period prior to diagnosis, but no significant difference in accident rate between OSAS and the general population for the 3-year period after initiation of CPAP. These findings indicate the importance of identifying patients with OSAS and the subsequent implementation of effective therapy. However, despite the reduction in accident rates with CPAP therapy in OSAS, there is evidence that driving simulator performance in OSAS patients remains worse than matched controls even after CPAP therapy [27].

\section{European regulations regarding driving in patients with OSAS}

The recognition that patients with untreated OSAS are at increased risk of MVA has resulted in several European Union (EU) member states developing and implementing regulations to control the ability of such patients to hold a driving licence. These regulations vary between countries, but generally permit successfully treated patients to continue or resume driving. However, some member states have no such regulations [28]. Inasmuch as driving allows rapid long-distance travel, involving easy crossing of the boundaries of member states, a driver with an unrestricted driving licence may drive in a member state where a restricted driving licence would be required, or even where driving would not be allowed at all. To circumvent this potential problem in a large geographical area with many borders, the EU has issued a basic document that constitutes a minimum set of rules that every member state needs to abide by. The most recent version of this document is the third driving licence directive, Directive 2006/126/EC, which entered fully into force in 2013. Annex III of the directive introduces the minimum requirement as regards a wide variety of medical conditions and distinguishes between private drivers (group 1: driving licence categories $\mathrm{A}$ and $\mathrm{B}$ ) and professional drivers (group 2: categories $\mathrm{C}$ and $\mathrm{D}$ ). Member states may also introduce more stringent rules in their own national legislation.

In recognition of the importance to road safety of driving with untreated OSAS, the committee established under directive 2006/126/EC on driving licences established a working group to propose adding obstructive sleep apnoea to Annex III. Each EU member state was invited to nominate an official representative to join the working group. The group met in Brussels in September 2012 and formed three subgroups to evaluate the following topics: 1) identifying the population at risk for OSAS; 2) establishing criteria for the provision of a driving licence to OSAS patients; and 3) education of key stakeholders such as police, professional drivers and the transport industry on untreated OSAS and its consequences. Over subsequent months, the working groups developed a series of recommendations, which culminated in a

\section{TABLE 1 Revision to Annex III of Directive 2006/126/EC (2014): obstructive sleep apnoea}

11.2. In the following paragraphs, a moderate obstructive sleep apnoea syndrome corresponds to a number of apnoeas and hypopnoeas per hour (Apnoea-Hypopnoea Index) between 15 and 29 and a severe obstructive sleep apnoea syndrome corresponds to an Apnoea-Hypopnoea Index of 30 or more, both associated with excessive daytime sleepiness

11.3. Applicants or drivers in whom a moderate or severe obstructive sleep apnoea syndrome is suspected shall be referred to further authorised medical advice before a driving licence is issued or renewed. They may be advised not to drive until confirmation of the diagnosis

11.4. Driving licences may be issued to applicants or drivers with moderate or severe obstructive sleep apnoea syndrome who show adequate control of their condition and compliance with appropriate treatment and improvement of sleepiness, if any, confirmed by authorised medical opinion

11.5. Applicants or drivers with moderate or severe obstructive sleep apnoea syndrome under treatment shall be subject to a periodic medical review, at intervals not exceeding three years for drivers of group 1 and one year for drivers of group 2, with a view to establish the level of compliance with treatment, the need for continuing treatment and continued good vigilance

Reproduced from [30] with permission from the European Union (http://eur-lex.europa.eu/). 
comprehensive report that was presented to the driving licence committee in June 2013 [29]. The working group also recommended specific guidelines for the provision of driving licences to patients with OSAS.

The committee accepted the recommendations of the working group and, following detailed consultation with member states, a revision to Annex III was implemented by the EC in June 2014 [30]. The details of this directive are presented in table 1, and are carefully written to allow clinical discretion in their implementation, and thus, hopefully to limit the likelihood that patients with OSAS will avoid seeking medical attention because of concern that driving will be prohibited as a consequence of the diagnosis. This latter concern is more likely to apply in the case of professional drivers who depend on the retention of their driving licence for employment. This revision becomes mandatory for implementation by all EU member states by December 31, 2015. These regulations represent the basic criteria for the provision of a driving licence to an individual with OSAS, but individual member states may adopt additional requirements as they see fit. No distinction is made in the regulations between group 1 and group 2 drivers, but closer follow-up is required for group 2 drivers to ensure compliance with therapy.

An obvious concern in implementing specific regulations for driving in patients with OSAS is that such regulations may deter patients with OSAS from coming forward for diagnosis and treatment. Thus, an important component of the process is to promote education of the general public on the dangers of driving with untreated OSAS, but also to promote awareness that effective treatment removes this danger and does not adversely affect the ability to hold a driving licence, either private or professional. Education of other relevant stakeholders, including police officers and employers in the transport industry on the association of OSAS with MVA risk is also a priority. While specific studies highlight the association of OSAS and sleepiness with MVA risk, OSAS and/or driver sleepiness are rarely investigated by police officers as a potential cause of MVA, resulting in a paucity of data on this issue.

\section{References}

1 Vaa T. Impairments, Diseases, Age and Their Relative Risks of Accident Involvement: Results from a Meta-analysis. Oslo, Institute of Transport Economics, 2003

2 Marshall SC, Man-Son-Hing M. Multiple chronic medical conditions and associated driving risk: a systematic review. Traffic Inj Prev 2011; 12: 142-148.

3 Smolensky MH, Di Milia L, Ohayon MM, et al. Sleep disorders, medical conditions, and road accident risk. Accid Anal Prev 2011; 43: 533-548.

4 Gonçalves M, Amici R, Lucas R, et al. Sleepiness at the wheel across Europe: a survey of 19 countries. J Sleep Res 2015; 24: 242-253.

5 Rodenstein D. Driving in Europe: the need of a common policy for drivers with obstructive sleep apnoea syndrome. J Sleep Res 2008; 17: 281-284.

6 Deegan PC, McNicholas WT. Pathophysiology of obstructive sleep apnoea. Eur Respir J 1995; 8: 1161-1178.

7 Rodenstein D. Sleep apnea: traffic and occupational accidents - individual risks, socioeconomic and legal implications. Respiration 2009; 78: 241-248.

8 Strohl KP, Brown DB, Collop N, et al. An official American Thoracic Society Clinical Practice Guideline: sleep apnea, sleepiness, and driving risk in noncommercial drivers. An update of a 1994 Statement. Am J Respir Crit Care Med 2013; 187: 1259-1266.

9 Tregear S, Reston J, Schoelles K, et al. Obstructive sleep apnea and risk of motor vehicle crash: systematic review and meta-analysis. J Clin Sleep Med 2009; 5: 573-581.

10 Ellen RL, Marshall SC, Palayew M, et al. Systematic review of motor vehicle crash risk in persons with sleep apnea. J Clin Sleep Med 2006; 15: 193-200.

11 Tefft BC. Prevalence of motor vehicle crashes involving drowsy drivers, United States, 1999-2008. Accid Anal Prev 2012; 45: 180-186.

12 Tippin J. Driving impairment in patients with obstructive sleep apnea syndrome. Am J Electroneurodiagnostic Technol 2007; 47: 114-12.

13 Arita A, Sasanabe R, Hasegawa R, et al. Risk factors for automobile accidents caused by falling asleep while driving in obstructive sleep apnea syndrome. Sleep Breath 2015 [In press; DOI: 10.1007/s11325-015-1145-7].

14 Ward KL, Hillman DR, James A, et al. Excessive daytime sleepiness increases the risk of motor vehicle crash in obstructive sleep apnea. J Clin Sleep Med 2013; 9: 1013-1021.

15 Catarino R, Spratley J, Catarino I, et al. Sleepiness and sleep-disordered breathing in truck drivers: risk analysis of road accidents. Sleep Breath 2014; 18: 59-68.

16 Karimi M, Hedner J, Häbel H, et al. Sleep apnea-related risk of motor vehicle accidents is reduced by continuous positive airway pressure: Swedish Traffic Accident Registry data. Sleep 2015; 38: 341-349.

17 Terán-Santos J, Jiménez-Gómez A, Cordero-Guevara J. The association between sleep apnea and the risk of traffic accidents. N Engl J Med 1999; 340: 847-851.

18 Karimi M, Hedner J, Lombardi C, et al. Driving habits and risk factors for traffic accidents among sleep apnea patients - a European multi-centre cohort study. J Sleep Res 2014; 23: 689-699.

19 Mulgrew AT, Nasvadi G, Butt A, et al. Risk and severity of motor vehicle crashes in patients with obstructive sleep apnoea/hypopnoea. Thorax 2008; 63: 536-541.

20 Di Milia L, Smolensky MH, Costa G, et al. Demographic factors, fatigue, and driving accidents: an examination of the published literature. Accid Anal Prev 2011; 43: 516-532.

21 Stevenson MR, Elkington J, Sharwood L, et al. The role of sleepiness, sleep disorders, and the work environment on heavy-vehicle crashes in 2 Australian states. Am J Epidemiol 2014; 179: 594-601.

22 Philip P, Chaufton C, Orriols L, et al. Complaints of poor sleep and risk of traffic accidents: a population-based case-control study. PLoS One 2014; 9: e114102. 
23 Horne J, Reyner L. Vehicle accidents related to sleep: a review. Occup Environ Med 1999; 56: 289-294.

24 George C. Driving and automobile crashes in patients with obstructive sleep apnoea/hypopnoea syndrome. Thorax 2004; 59: 804-807.

25 Tregear S, Reston J, Schoelles K, et al. Continuous positive airway pressure reduces risk of motor vehicle crash among drivers with obstructive sleep apnea: systematic review and meta-analysis. Sleep 2010; 33: 1373-1380.

26 George CF. Reduction in motor vehicle collisions following treatment of sleep apnoea with nasal CPAP. Thorax 2001; 56: 508-512.

27 Vakulin A, Baulk SD, Catcheside PG, et al. Driving simulator performance remains impaired in patients with severe OSA after CPAP treatment. J Clin Sleep Med 2011; 7: 246-253.

28 Alonderis A, Barbé F, Bonsignore M, et al. Medico-legal implications of sleep apnoea syndrome: driving license regulations in Europe. Sleep Med 2008; 9: 362-375.

29 McNicholas WT, Bencs Z, De Valck E, et al. New standards and guidelines for drivers with obstructive sleep apnoea syndrome. http://ec.europa.eu/transport/road_safety/pdf/behavior/sleep_apnoea.pdf Date last accessed: October 22, 2015. Date last updated: 2013.

30 Revision to Annex III of EU Driving Licence Directive Regarding Obstructive Sleep Apnoea Syndrome. http:// eur-lex.europa.eu/legal-content/EN/TXT/?uri=uriserv:OJ.L_.2014.194.01.0010.01.ENG Date last accessed: October 22, 2015. Date last updated: 2014 